\title{
A proximidade dos correspondentes internacionais em tempos de Covid-19
}

The proximity of international correspondents in times of Covid-19

\author{
Jaime Lourenço - NIPC@M \\ Universidade Autónoma de Lisboa \\ Iscte/CIES- Instituto Universitário de Lisboa \\ jlourenco@autonoma.pt
}

Carlos Pedro Dias- NIPC@M

Universidade Autónoma de Lisboa

OBSERVARE

cpdias@autonoma.pt

doi: $x x x x x x x x x x x$

\begin{tabular}{|c|c|c|}
\hline Recebido / Received & Aceite / Accepted & Publicado / Published \\
30.09 .2020 & 10.11 .2020 & 1.06 .2021 \\
\hline
\end{tabular}

Como citar este capítulo / How to quote this chapter:

Lourenço, J. \& Dias, C. P. (2021). "A proximidade dos correspondentes internacionais em tempos de Covid-19". In Reis, B., Um mundo de incertezas; as leituras possíveis de um tempo pandémico (pp. 72-94). Lisboa: NIP-C@M \& UAL, disponível em $x x x x x x x x x$. DOI $x x x x x x x$ 


\section{Introdução}

Nos primeiros meses da pandemia associada ao coronavírus foi realizado um estudo (Lourenço \& Dias, 2020), sobre as alterações das rotinas produtivas dos correspondentes internacionais de diversos órgãos de comunicação social portugueses. Tratava-se de uma análise enquadrada no quadro global do impacto da Covid-19 no jornalismo. Passados alguns meses (e depois de um desconfinamento e de um novo confinamento), será altura de revisitar o tema e tentar perceber se algumas das tendências verificadas no referido estudo se acentuaram ou, pelo contrário, regressaram à anterior normalidade. A atual conjuntura internacional é particularmente rica em acontecimentos mediáticos ${ }^{1}$ que, disputam o palco à pandemia, constituindo, por isso mesmo, um interessante campo de observação e análise. E mantém-se completamente atual o importante papel que, em tempos de crise, os media e em particular a televisão desempenham enquanto aglutinadores da sociedade, de forma a satisfazer necessidades individuais e a cultivar o espírito de comunidade (Hellman \& Riegert, 2012: 170)

Olhamos, portanto, para os correspondentes internacionais, para as conclusões do estudo anteriormente realizado do qual partimos e para a realidade do trabalho dos correspondentes internacionais numa fase em que a pandemia já se tornou quase uma normalidade, e é sobre essa normalidade a que estes jornalistas se dedicam, bem como outros acontecimentos

1 Alguns exemplos: as eleições nos EUA em Novembro (e a respetiva campanha eleitoral), o Brexit, o terrorismo islâmico na Europa, o conflito do Nagorno-Karabakh, etc. 
de interesse jornalístico. De que forma se alterou ainda mais o trabalho dos correspondentes ou se mantiveram as alterações já detetadas anteriormente? Será que a tendência de globalização dos media e das redes sociais ainda requer a presença de um jornalista nacional em países de onde recebemos imagens, sons e informação a partir de agências de notícias ou dos media locais? Como se compatibiliza a existência de um correspondente num determinado país com o envio de diversas equipas adicionais de reportagem para cobrir determinados eventos?

\section{O correspondente internacional}

Historicamente, os media têm atuado como edificadores de nações ${ }^{2}$, em que, além de uniformizarem experiências, fornecem uma plataforma para que os cidadãos troquem opiniões sobre a vida pública comum, tal como Habermas preconiza, mas também através de comparações, discutindo as semelhanças e diferenças, entre os cidadãos e os sistemas de outras nações. A correspondência internacional permite, então, que os cidadãos estejam cientes de acontecimentos e questões dos vários cantos do mundo e como estes podem influenciar a forma como as pessoas, bem como as instituições interagem e comunicam entre si e como se relacionam com as de outras nações (Terzis, 2015: 297).

\footnotetext{
2 As notícias, além de serem o principal produto do jornalismo contemporâneo (Traquina, 2002: 9), refletem a sociedade ao espelharem as suas preocupações e interesses (Tuchman, 2002: 91). Tal como Robert E. Park (2002) enuncia, as notícias são uma forma de conhecimento informal ao estarem relacionadas com a participação na vida política da sociedade, transmitindo informações e permitindo a dinamização da atividade económica.
} 
Os correspondentes funcionam como uma âncora de determinado país (Rodrigues, 2008: 53), sendo, acima de tudo, jornalistas e, portanto, partilham de valores, deveres, princípios éticos e formas de olhar o mundo muito próprias assentes num compromisso público com sentido de credibilidade. No fundo, constituem-se enquanto uma comunidade interpretativa, como propõe Barbie Zelizer (2000), em que se parte do princípio de que a autoridade dos jornalistas deriva da sua presença nos acontecimentos, de acordo com a ideologia da autenticidade da "testemunha ocular". Neste quadro, os jornalistas possuem as qualificações necessárias para avaliar determinado acontecimento crítico (Zelizer, 2000: 40 e 41). É, neste contexto, que a presença do correspondente no local dos factos e dos acontecimentos é a forma de veicular e apresentar à sociedade o ambiente político, económico, social e cultural que presenceia no país em que se encontra. Contudo, apesar de a atividade informativa ser a principal razão de ser do jornalismo, "o jornalista analisa, comenta, exprime opiniões. Observa, interpreta e narra. Gere o acesso ao 'espaço público' de outras palavras consideradas 'legítimas': actores políticos e sociais, intelectuais, cidadãos em geral" (Mesquita, 2003: 72 e 73).

Neste sentido, os factos são reconfigurados através da linguagem, contextualizados e interpretados pelo jornalista que os apreende. O 'agir' jornalístico pressupõe a procura, a seleção, a investigação e a interpretação dos acontecimentos (Mesquita, 2005: 9). A jornalista Daniela Santiago (2013), atual 
correspondente da RTP em Madrid, também defende a mesma perspetiva, quando afirma que para o jornalista, o jornalismo não é uma mera transmissão de informação, encarando de forma mais profissional, ética, correta e mais objetivo, assumir, perante o público, os jornalistas enquanto seres humanos (Santiago, 2013).

Ao falarmos de correspondentes, autonomia é a palavra-chave (Rodrigues, 2008: 53). De acordo com Ana Luísa Rodrigues (2008), estes jornalistas, ao estarem menos expostos às hierarquias organizacionais, gozam de alguma liberdade de proposta de peças jornalísticas e de movimentos, sobretudo se o país em que se encontram não estiver no centro da atenção mediática. No entanto, a experiência leva-os a canalizar as escolhas de temas a abordar para a agenda mainstream (Baptista \& Henriques, 2015: 202). Por sua vez, os editores que se encontram nas redações do órgão para o qual trabalham servem de 'barómetro' para os correspondentes avaliarem o que é ou não interessante para o público. Deste modo, as rotinas estão estruturadas em dois eixos: uma interação de trabalho no local onde os correspondentes estão baseados e outra com a redação central do órgão para que trabalham (Rodrigues, 2008: 52).

A correspondência internacional não se reduz ao jornalismo, desde sempre desempenhou um papel de relação diplomática e de intercâmbio cultural (Leal-Adghirni, Pinson, \& Ruellan, 2016). O correspondente internacional é considerado como um cidadão do mundo, um cosmopolita, possuidor de uma cultura híbrida que cria "novas formas culturais, compósitas, a partir de 
cruzamentos" (Fortuna \& Santos Silva, 2001: 432). Este jornalista é alguém que vive permanentemente entre duas (ou mais) linhas paralelas: duas realidades, dois países, duas culturas, dois fusos horários, duas línguas (Rodrigues, 2008: 47).

Desta forma, os correspondentes internacionais cumprem funções de reportar as notícias, de analisar e comentar os acontecimentos com a sua perspetiva (Sambrook, 2010: 8), acentuando uma operação de domesticação, uma vez que a informação internacional é produzida "à medida", para um determinado órgão, e não só baseada em envios de cadeias noticiosas cujas perspetivações são necessariamente mais gerais e vastas (Rodrigues, 2008: 52).

Com a emergência da Internet e das redes sociais, a informação jornalística que antes se situava geograficamente distante, agora está, literalmente, à distância de um clique. Para inúmeros jornalistas que se debruçam sobre a informação internacional a partir das suas secretárias com acesso online imediato a várias fontes, informação e redes sociais, o conceito de correspondente internacional é redundante, uma vez que qualquer jornalista consegue ter acesso a qualquer fonte a partir de ferramentas online como o Skype, Facetime ou Zoom e os tradicionais vox pops nas ruas hoje estão espelhados em redes sociais como o Twitter (Bebawi \& Evans, 2019: 24). Richard Sambrook (2010) realça a diminuição do número de correspondentes internacionais como uma consequência destas novas possibilidades permitidas pela tecnologia, principalmente nos países do Ocidente. No entanto, continua a haver valor em destacar um jornalista 
como correspondente de forma a contextualizar, cobrir e analisar os vários acontecimentos (Sambrook, 2010). Porém, há exemplos, como o caso particular de Bruxelas, em que o número de correspondentes aumentou ligeiramente nos últimos anos (Terzis, 2015: 300). No mesmo sentido, Cristina Archetti (2012) afirma que a luta pela sobrevivência económica num contexto bastante competitivo que está a levar à diminuição dos correspondentes internacionais, está também a impulsionar uma maior confiança nestes jornalistas (Archetti, 2012: 853).

De acordo com o estudo Mapping Foreign Correspondence in Europe, em 2013 encontravam-se mais de 6600 correspondentes internacionais a trabalhar para mais de 130 órgãos de comunicação nos 27 Estados-Membro da União Europeia (Terzis, 2015: 297). O mesmo estudo concluiu, entre outros aspetos, que grande parte dos correspondentes internacionais deixaram de trabalhar a tempo inteiro na imprensa, para passarem a trabalhar em regime freelancer, dedicando-se a vários meios, por vezes de diferentes países (Terzis, 2015: 298).

\section{Desenho do Estudo}

Recorde-se que o estudo citado (Lourenço \& Dias, 2020) partiu da auscultação de 15 jornalistas que trabalham para vários meios e órgãos portugueses, desde a imprensa, rádio, televisão e agência noticiosa. A estes jornalistas foi-lhes proposto um inquérito por questionário via e-mail que procurava entender como as rotinas de trabalho se alteraram nos primeiros meses 
de pandemia (Março, Abril, Maio e Junho de 2020). O inquérito procurou, na altura, recolher dados acerca dos principais temas a que os correspondentes se dedicaram, o contacto com fontes, géneros jornalísticos e os principais desafios enfrentados durante este período. As respostas obtidas dividiram-se entre televisão, agência noticiosa, rádio e imprensa, e registou-se a particularidade de ter respostas de correspondentes "recentes" (menos de 5 anos) a par de outros com mais de 20 anos de terreno.

Para aferir da evolução verificada desde o momento da realização do inquérito referente aos primeiros meses de pandemia até ao presente (Novembro 2020), foram analisados diversos exemplos a partir dos órgãos de comunicação social, cujos correspondentes participaram no inquérito. Trata-se do único modelo de comparação ao nosso dispor, uma vez que a distribuição de um novo inquérito não se revelou possível devido a questões ligadas à disponibilidade dos órgãos de comunicação social.

\section{Os correspondentes internacionais portugueses}

Existem correspondentes internacionais portugueses um pouco por todo o mundo, com um maior foco nas principais capitais europeias, países de língua oficial portuguesa, nos centros de decisão política ocidental (como Bruxelas e Washington DC), entre outros. Tradicionalmente, o maior investimento em correspondentes internacionais tem sido feito pelos órgãos de comunicação social de domínio público, como a Agência Lusa e a RTP. A situação profissional dos correspondentes portugueses 
varia muito. Desde jornalistas que pertencem aos quadros da empresa, a freelancers pagos "à peça”.

Uma das principais conclusões do nosso estudo original era a existência comprovada de uma maior autonomia editorial por parte do jornalista correspondente quando comparado com um jornalista sediado numa redação. Esta informação é consistente com aquilo que Ana Luísa Rodrigues (2008) referia quando afirmava que autonomia é um conceito central ao abordarmos as rotinas dos jornalistas correspondentes. Segundo a autora, isto deve-se à gestão de tempo dessa rotina que é muito personalizada por cada correspondente, mas também, e sobretudo, na seleção dos temas e na diversidade de trabalhos que podem realizar (Rodrigues, 2008: 53). Para os jornalistas auscultados, a seleção dos tópicos é, na grande maioria, decidida em conjunto, entre o correspondente e o seu editor sediado em Portugal, sendo os três principais temas, a que normalmente se debruçam, a Política, a Economia e a Segurança.

Continuando a análise comparativa dos dados obtidos verificase que a notícia $(53,3 \%)$ e a reportagem $(33,3 \%)$ são os principais géneros jornalísticos utilizados por estes profissionais. Os correspondentes inquiridos confirmaram também que a essência do jornalista correspondente é a proximidade que têm com o acontecimento. Tal como Zelizer (2000) afirma, "a autoridade dos jornalistas deriva da sua presença nos acontecimentos" (Zelizer, 2000: 41), o que é extensível ao trabalho dos jornalistas correspondentes. Bebawi \& Evans (2019) são perentórios quando indicam que "continua a existir a necessidade de 
repórteres no terreno para cobrir os acontecimentos" (Bebawi \& Evans, 2019: 25). Neste sentido, esta cobertura "consiste em observar, interpretar e narrar a 'realidade social', da qual são igualmente construtores" (Mesquita, 2005; 22).

Aqui chegados encontramos uma das questões que merece especial análise: um dos participantes no inquérito afirma que a maior parte do seu trabalho é de "análise". O facto de se tratar de um inquérito anónimo não permite aprofundar esta observação, mas já anteriormente se vinha a notar uma certa tendência, sobretudo nos canais de televisão de notícias, de transformar o correspondente num "comentador privilegiado". Alguém que já não sai do estúdio (ou do escritório do correspondente) e que comenta temas da atualidade do país em que vive, principalmente em direto. Uma situação que pode ser considerada menos positiva, à luz da questão da proximidade, mas que não difere assim tanto da realidade de muitos dos trabalhos jornalísticos. Sarah Smith, editora da BBC Escócia, refere $^{3}$, quando questionada sobre este "afastamento", o facto de muitas vezes produzir conteúdos sobre o parlamento escocês e recorrer, normalmente, à gravação de um "vivo" à porta do parlamento sem ter, no entanto, necessidade de lá entrar para recolha ou validação de informação. Encontramos diariamente exemplos desta situação com correspondentes da RTP

\footnotetext{
3 BBC News, 26 de Março de 2020, "How virus has changed the way reporters work", disponível em https://www.bbc.com/news/uk-scotland-52052447.

4 Gravação realizada em frente à câmara de televisão "simulando" um direto. Permite ver o repórter e o local onde este se encontra, num processo de validação do conteúdo através da ligação ao local onde a informação foi obtida ou a que diz respeito. Trata-se de um recurso muito utilizado nas redações de televisão perante a ausência de imagens que possam ser utilizadas para a construção de uma peça tradicional de televisão.
} 
(Rosário Salgueiro em Paris, Daniela Santiago em Madrid) ou da SIC (caso mais evidente ainda de Luís Costa Ribas, correspondente sediado em Boston). Trata-se de um modelo que poderá ser explicado, sobretudo, por razões económicas ${ }^{5}$, mas que é também fruto de alguma evolução do modelo de produção de notícias. Um jornalista numa redação é também, muitas vezes, chamado a produzir peças com conteúdos de agências de notícias ou de outros colegas. E em muitos casos também não esteve no local, nem falou com as pessoas envolvidas. Ora, um correspondente internacional terá acesso a muita informação local, terá uma rede de contactos a que pode recorrer localmente para esclarecer questões e terá, sempre, uma maior proximidade com os temas do que um qualquer outro jornalista ou comentador em Lisboa.

Todavia, verificámos que estes profissionais têm em consideração que se dirigem para o público português, independentemente do meio para que trabalham e $46,7 \%$ dos jornalistas inquiridos considera que um protagonista português de determinado acontecimento constitui um valor notícia, sendo a presença de protagonistas portugueses habitual no trabalho realizado por estes profissionais. Tal remete para a proximidade enquanto valor-notícia, tal como enunciado por Traquina (2002), uma vez que um protagonista português pode-se constituir como relevante em termos geográficos e culturais.

5 Os custos de aluguer de um operador de câmara ou repórter de imagem e as respetivas despesas de deslocação, estadia e envio do conteúdo. 
Questionados sobre os principais desafios que os correspondentes internacionais portugueses enfrentam, os jornalistas afirmaram, entre outros aspetos, questões relacionadas com a seleção de informação mais relevante para o público português, tendo que traduzir realidades distintas da portuguesa. Vários sublinham a explicação de factos, em que tentam resumir a informação quotidianamente, ao mesmo tempo que procuram ser mais explicativos e simplificar questões complexas. Um dos inquiridos aponta como desafio "traduzir para a linguagem televisiva, assuntos com vários detalhes, por vezes históricos, que são importantes para contextualizar, mas não são familiares para os portugueses". Este correspondente acrescenta que tenta "que o resultado final fique bem resumido, explicado e que não seja superficial".

Outros aspetos mencionados passam pela dificuldade de integração nos primeiros anos de correspondência quer a nível do estabelecimento como também da constituição de uma nova agenda de contactos. No entanto, passam também, por vezes, por um trabalho solitário, em que o jornalista tem que se deslocar em transportes públicos, colocando em causa a rapidez em chegar aos acontecimentos.

Entre o "permanente estado de alerta, estudo e reflexão de múltiplos temas, imprevisibilidade e viagens constantes", a diferença de fuso horário, também é referido o "pouco ou nenhum feedback" e o escasso diálogo com a sede, traduzindo-se numa "pouca oportunidade de diálogo com colegas de trabalho" além dos editores. 


\section{O primeiro impacto da Covid-19}

O coronavírus, que inicialmente abalou a China e os países asiáticos, rapidamente se alastrou por todo o mundo, provocando uma crise pandémica sem precedentes. Crise essa que se espalhou por todos os setores das sociedades, incluindo os media. De acordo com o relatório do OberCom (2020), o meio em que os impactos terão sido menos acentuados terá sido a rádio, enquanto que a imprensa terá sido o meio mais afetado por esta crise, expondo a fragilidade dessas empresas (OberCom, 2020: 4).

Uma vez que os correspondentes internacionais portugueses estão espalhados um pouco por todo o mundo, tiveram, também, que lidar com esta crise. Perante os dados apurados, podemos afirmar que as rotinas dos correspondentes internacionais portugueses alteraram profundamente perante a crise criada pela pandemia. 93,3\% dos correspondentes inquiridos afirma que, nos primeiros meses da crise pandémica (Março, Abril, Maio e Junho de 2020), o seu trabalho foi, maioritariamente, dedicado à cobertura da Covid-19. Motivo que levou a que deixassem de abordar temas que eram habituais nas suas rotinas. Entre os principais temas, a Saúde passou a ser o principal, seguido da Política, da Economia e da Segurança. Estes últimos, provavelmente, também em função da pandemia.

Se a proximidade é um factor essencial na atividade jornalística, 60\% destes correspondentes sentiram que deixaram de 
estar próximos da notícia. Tal implica debilidades na cobertura jornalística dos acontecimentos e coloca em causa a informação veiculada, neste caso, pelos correspondentes, uma vez que a função da observação no terreno se torna fragilizada. Contudo, além desse afastamento da notícia, $80 \%$ dos jornalistas inquiridos afirmaram que o número de horas de trabalho aumentou, chegando, em alguns casos, a trabalharem o dobro de horas diárias do que em tempos normais.

Os principais géneros jornalísticos continuaram a ser a notícia $(66,7 \%)$, a reportagem $(13,3 \%)$ e a entrevista $(13,3 \%)$. No entanto, para a execução destes trabalhos, o contacto com fontes torna-se fundamental, tal como Felisbela Lopes aponta, as fontes de informação jornalística constituem-se como ponto fulcral para a compreensão dos conteúdos jornalísticos (Lopes, 2016). Mas em tempos de contacto presencial reduzido ou mesmo inexistente, $73,3 \%$ dos correspondentes refere que teve dificuldades em contactar fontes durante este período, o que, por si só, revela um obstáculo ao normal decorrer da atividade jornalística. Como forma de contornar estas dificuldades no contacto com as fontes, os correspondentes recorreram, em grande medida, a ferramentas como o Skype ou o Zoom. Também o tradicional telefone foi um dos meios utilizados para esse contacto, evitando assim a interação presencial. No entanto, embora o contacto com as fontes seja distanciado, a utilização de máscara, a desinfeção pessoal e do espaço de trabalho, no que diz respeito às medidas de proteção que os correspondentes internacionais adotaram, passou a fazer parte da rotina diária. 
Quanto às principais adversidades com que se depararam para o exercício do seu trabalho, os jornalistas afirmaram que o risco de contágio e o confinamento obrigatório foram transversais e também os afetaram, tanto enquanto profissionais, como seres humanos. Elegeram também o contacto com as fontes como uma das principais dificuldades, nomeadamente as complicações em contactar alguém via telefone, uma vez que as empresas encerraram, ou conseguir, no caso da televisão, autorizações para gravar em locais específicos, como hospitais.

A acrescentar a estas questões, este período também foi de adaptação e aprendizagem de novas ferramentas e softwares aos quais os jornalistas não estavam acostumados. Isto a acrescentar à "quantidade gigantesca de informação para tratar dada a dimensão do país e a complexidade da relação entre informações políticas e informações sobre saúde", tal como indica um dos jornalistas.

Um dos correspondentes auscultado, mencionou ainda que, por questões de segurança, teve que regressar a Portugal, o que implica que um órgão de informação português deixou de ter um jornalista presente em determinado país, o que, certamente, criou uma debilidade da informação sobre esse país nesse órgão de comunicação.

No entanto, os jornalistas também sentiram algumas dificuldades em escapar à agenda mediática sobre a Covid-19 e apresentar histórias que não estivessem relacionadas com a pandemia. 


\section{Terão os correspondentes voltado a ficar próximos do acontecimento?}

Tal como referido anteriormente, não foi possível realizar um novo inquérito para perceber se as rotinas produtivas destes jornalistas se mantiveram nos meses seguintes à primeira análise. Selecionámos ${ }^{6}$, portanto, alguns casos de trabalhos desenvolvidos pelos correspondentes internacionais na última semana de Outubro e na primeira semana de Novembro de 2020.

\section{O colapso das unidades de cuidados intensivos em} Espanha

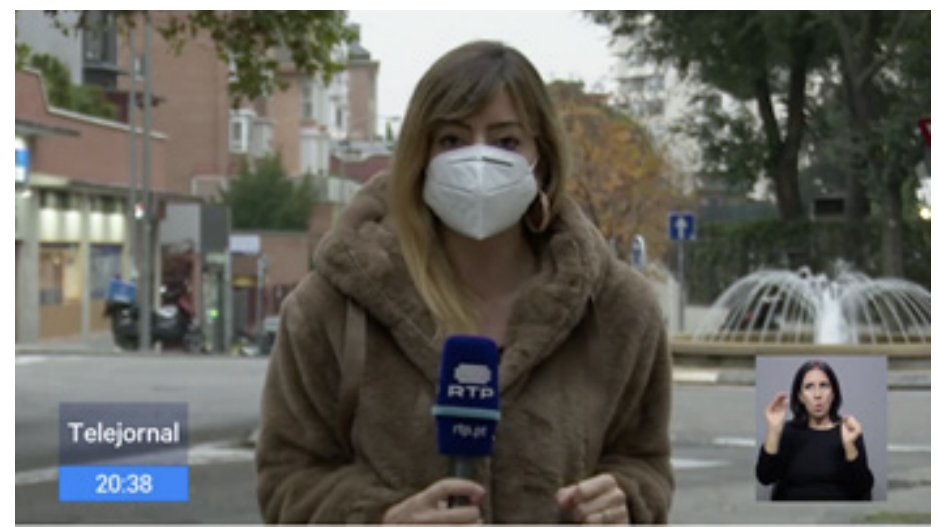

Figura 1 A correspondente da RTP em Madrid, Daniela Santiago.

Num momento em que, em Espanha, se registaram quase 20 mil casos de infeção por Covid-19 em 24 horas, os serviços

6 Nesta seleção adoptámos casos de televisão, uma vez que nos dão a entender os cuidados de proteção do jornalista e o contexto em que se encontram de forma mais esclarecedora. 
hospitalares começaram a acusar rutura e aumentaram os protestos contra as medidas de restrição aplicadas pelo governo.

Olhamos para a reportagem ${ }^{7}$ da correspondente da RTP em Madrid, Daniela Santiago, onde tem como fontes, nos moldes normais de reportagem em televisão, médicos espanhóis que relatam o estado em que as unidades de cuidados intensivos se encontram, aproximando-se de um momento de rutura. Nesta peça, a jornalista aparece em "vivo", a utilizar máscara, apresentando dados sobre a lotação das unidades hospitalares. Percebemos, portanto, que há uma preocupação em voltar ao contacto presencial com as fontes, mas atendendo às medidas de proteção e distanciamento sempre que possível. Na mesma reportagem, são utilizadas imagens do parlamento espanhol, em que o ministro da saúde discursa, bem como imagens de protestos na Catalunha e em La Rioja. Estas imagens não foram captadas pela equipa da RTP mas, na impossibilidade de estarem presentes no local, recorreram a estas imagens difundidas por outros meios.

\section{A resposta europeia à pandemia}

No final de Outubro o Conselho Europeu reuniu para discutir a resposta que os vários países estão a dar à "segunda vaga" de Covid-19. Esta reunião informal, feita através de videoconferência, com os 27 chefes de Estado e de governo,

7 RTP, 28 de Outubro de 2020, "Unidades de cuidados intensivos de Espanha perto do colapso", disponível em: https://www.rtp.pt/noticias/mundo/unidades-de-cuidadosintensivos-de-espanha-perto-do-colapso_v1270935? fbclid=IwAR3UYfC-AreS5mc5u8Zm dheVeso05oi8dT2HRoclOJLreoXbIFTNtHbe6 4 
analisaram a situação e decidiram que, apesar das várias medidas restritivas, nenhum líder quis fechar fronteiras ou paralisar completamente a atividade económica (Siza, 2020).

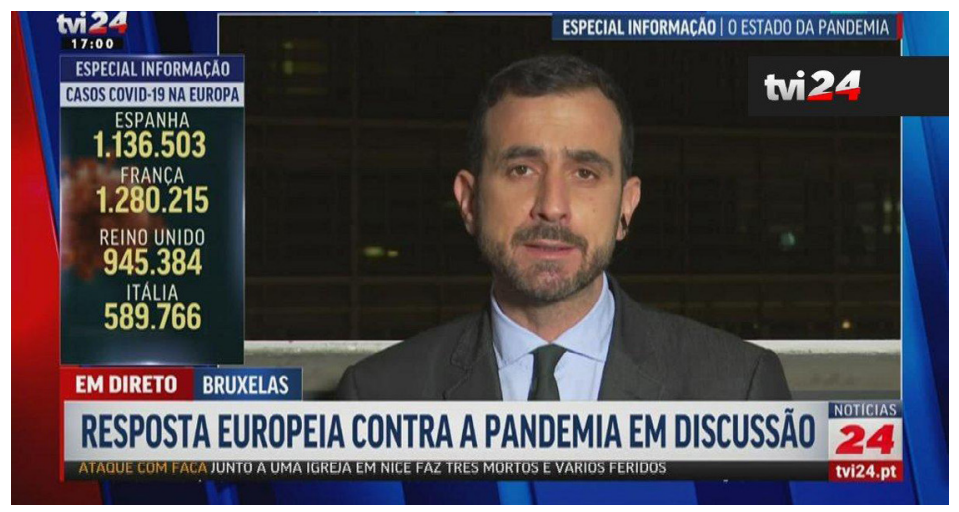

Figura 2 O Correspondente da TVI em Bruxelas, Pedro Moreira.

Na TVI24, o correspondente em Bruxelas, Pedro Moreira, entrou em direto ${ }^{8}$ dando conta dos temas tratados na reunião e as realidades de vários países europeus, bem como estes estão a enfrentar a "segunda vaga" da pandemia. Neste direto, o jornalista não interpelou nenhuma fonte e não é identificável o local onde se encontra, limitando-se a transmitir as informações sobre a reunião do Conselho Europeu e interagindo com a pivô em Lisboa. Ora, estes dados vão ao encontro daquilo que a editora da BBC na Escócia, Sarah Smith refere quando diz que muitas vezes apenas grava vivos em frente ao parlamento escocês para as suas peças, mas não chega a entrar no edifício para recolher informação, uma vez que esta está disponível através de outras

8 TVI24, 29 de Outubro de 2020, “Covid-19: Conselho Europeu discute resposta contra a segunda vaga", disponível em: https://tvi24.iol.pt/videos/internacional/covid-19-conselhoeuropeu-discute-resposta-contra-a-segunda-vaga/5f9b027e0cf2c785554ca235\#/ 
vias. No caso da TVI24, verificámos o mesmo estilo neste direto, em que o jornalista apenas se limita a transmitir informações e o local do direto não chega a ser identificável.

\section{A campanha para as eleições dos EUA}

As eleições americanas constituem, sem qualquer dúvida, um espaço privilegiado de observação das rotinas de produção de notícias. Quer no que diz respeito aos correspondentes locais (SIC e RTP), quer aos enviados de ambas as estações.

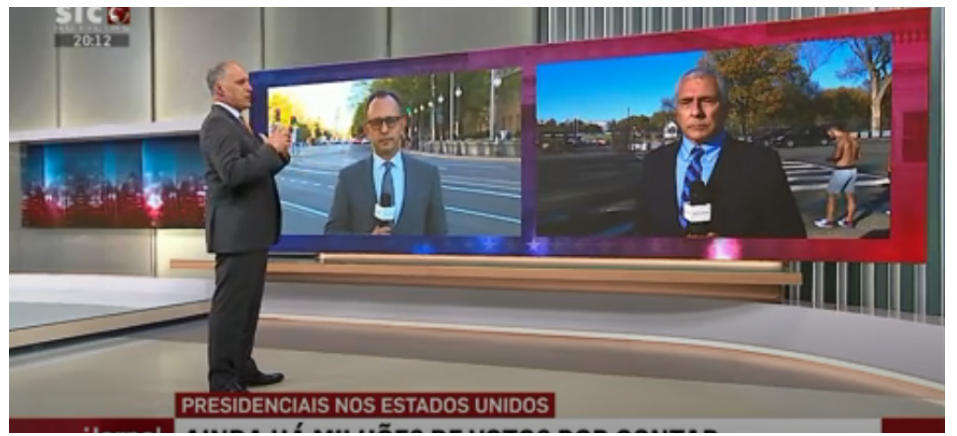

Figura 3 Frame do Jornal da Noite da SIC, com pontos de direto do enviado Ricardo Costa (esq.) e do correspondente Luís Costa Ribas (dir.) a propósito das eleições dos EUA.

O caso do correspondente da SIC nos Estados Unidos da América é particularmente interessante. Apesar do reforço da equipa com a presença de um enviado, no caso o jornalista Ricardo Costa (também diretor de informação da estação), assistimos a uma alteração na rotina habitual do correspondente. De volta "à rua", neste caso até de volta a Washington D.C., onde a SIC manteve durante alguns anos um escritório e um 
correspondente permanente. Será uma situação excecional atendendo à dimensão mediática das eleições ou marcará, pelo contrário, um regresso ao modelo mais tradicional de trabalho jornalístico? Registe-se que o correspondente da SIC (bem como o enviado especial), aparece frente à câmara, em direto, sem máscara ou outra forma de proteção visível.

O correspondente da SIC nos Estados Unidos regressou quase de imediato à sua base habitual de trabalho, em Boston, retomando o formato habitual do seu trabalho para a referida estação de televisão. Um trabalho quase de comentador/ explicador de um país. E um trabalho escorado pelas suas inúmeras fontes no país. "Ter boas fontes conduz a mais boas fontes" (Ribas, 2018: 75) é uma expressão que resume bem a forma de estar profissional deste correspondente.

Já a RTP, nas eleições norte-americanas, parece manter a lógica de reportagem de rua e, os trabalhos emitidos no dia 8 de novembro, já em plena festa de consagração do Presidente eleito, são um bom exemplo de reportagem "de rua", junto das pessoas.

\section{Considerações finais}

Se num primeiro momento havíamos verificado que houve uma transformação considerável no desempenho profissional dos correspondentes internacionais portugueses - desde o sentimento de distância das notícias; o principal tema tratado 
passar a ser a saúde; um aumento do número de horas de trabalho; ou a adaptação a novas ferramentas de trabalho (como o Skype ou o Zoom) -, no presente estudo, procurámos aferir as alterações verificadas no trabalho dos correspondentes internacionais das televisões portuguesas, relativamente ao momento em que foi realizado o primeiro estudo (que nos serve de termos de comparação). A escolha da televisão, ou seja, de um olhar de fora para dentro, permite perceber que o trabalho destes correspondentes sofreu novas alterações. Para lá de um mais que evidente regresso à "rua" e à proximidade com o dia-a-dia, parece registar-se uma quase normalização da vida dos correspondentes. Com uma agenda já não virada para a Covid-19 exclusivamente. Com espaço para outros acontecimentos mediáticos, mas sempre num espaço público claramente dominado pela presença da crise pandémica. Seja enquanto fator condicionante dos assuntos de reportagem (como por exemplo nas Eleições dos EUA, fortemente marcadas pelo coronavírus), seja enquanto fator condicionador do trabalho do repórter (máscara, microfone revestido a plástico, etc.).

Este estudo abre portas para uma eventual investigação futura que aprofunde as alterações provocadas nas rotinas produtivas dos correspondentes internacionais, agora já de forma prolongada sob o efeito da Covid-19. Para tal, deveria ser lançado um novo inquérito junto dos correspondentes, procurando ainda alargar o número de inquiridos e recorrendo também a entrevistas personalizadas. 


\section{Bibliografia}

Archetti, C. (2012). Wich Future for Foreign Correspondence? London foreign correspondents in the age of global media. Journalism Studies, 13(5-6), pp. 847-856.

Baptista, C., \& Henriques, C. (2015). Foreign Correspondents in Portugal. In G. Terzis (Ed.), Mapping Foreign Correspondence in Europe. Nova lorque: Routledge, pp. 203-212.

Bebawi, S., \& Evans, M. (2019). The Future Foreign Correspondent. Sydney: Palgrave Macmillan.

Fortuna, C., \& Santos Silva, A. (2001). A cidade do lado da cultura: espacialidades sociais e modalidades de intermediação cultural. In B. d. Santos (Ed.), Globalização, Fatalidade ou Utopia?. Porto: Edições Afrontamento, pp. 409-461.

Leal-Adghirni, Z., Pinson, G., \& Ruellan, D. (2016). Correspondentes internacionais - introdução. Sur le journalisme, About journalism, Sobre jornalismo, 5(1), pp. 12-14.

Lourenço, J., \& Dias, C. P. (2020). Portuguese International Correspondents: How Covid-19 affected their work. In J. S. González, \& J. G. Camacho (Edits.). Comunicación Especializada: Historia y Realidad Actual. Madrid: McGraw Hill, pp. 431-439.

Mesquita, M. (2003). O Quarto Equívoco - O poder dos media na sociedade contemporânea (1 $1 \underline{a}$ ed.). Coimbra: MinervaCoimbra.

Mesquita, M. (2005). Teorias e práticas do jornalismo: do telégrafo ao hipertexto. Trajectos, 6, pp. 9-24.

OberCom. (2020). Impacto do Coronavírus e da crise pandémica no Sistema mediático português e global. Versão II. Lisboa.

Park, R. E. (2002). As Notícias como uma forma de conhecimento: um capítulo na sociologia do conhecimento. In J. P. Esteves (Ed.), 
Comunicação e Sociedade: Os Efeitos dos Meios de Comunicação de Massa. Lisboa: Livros Horizonte, pp. 35-60.

Ribas, L. C. (2018). Uma Vida em Directo. Lisboa: Oficina do Livro.

Rodrigues, A. L. (2008). Aos Olhos do Mundo: Portugal e os Portugueses retratados por correspondentes Estrangeiros. Lisboa: Livros Horizonte.

Sambrook, R. (2010). Are Foreign Correspondents Redundant? Oxford: Reuters Institute for the Study of Journalism.

Santiago, D. (2013). Ameaças e Desafios do Jornalismo Contemporâneo. Comunicação Pública, 8(14), pp. 95-135.

Siza, R. (2020, Outubro 29). Líderes da UE não vão fechar fronteiras nem paralisar a economia em reacção à segunda vaga da pandemia, Público, Novembro 3, 2020, disponível em: https://www.publico. pt/2020/10/29/mundo/noticia/lideres-ue-nao-vao-fechar-fronteirasparalisar-economia-reaccao-segunda-vaga-pandemia-1937281

Terzis, G. (2015). The 'Professional Strangers' of Europe at the Dawn of the 21st Century. In G. Terzis (Ed.), Mapping Foreign Correspondence in Europe. New York: Routledge, pp. 297-313.

Traquina, N. (2002). O que é Jornalismo (1a ed.). Lisboa: Quimera.

Tuchman, G. (2002). As notícias como uma realidade construída. In J. P. Esteves (Ed.), Comunicação e Sociedade - Os efeitos dos meios de comunicação de massa. Lisboa: Livros Horizonte, pp. 37-50.

Zelizer, B. (2000). Os jornalistas enquanto comunidade interpretativa. Revista de Comunicação e Linguagens(27), pp. 33-61. 